\title{
Mike Land: a personal remembrance
}

\author{
Eric Warrant ${ }^{1}$ (1)
}

Received: 23 January 2022 / Revised: 3 February 2022 / Accepted: 4 February 2022 / Published online: 28 February 2022

(c) The Author(s), under exclusive licence to Springer-Verlag GmbH Germany, part of Springer Nature 2022

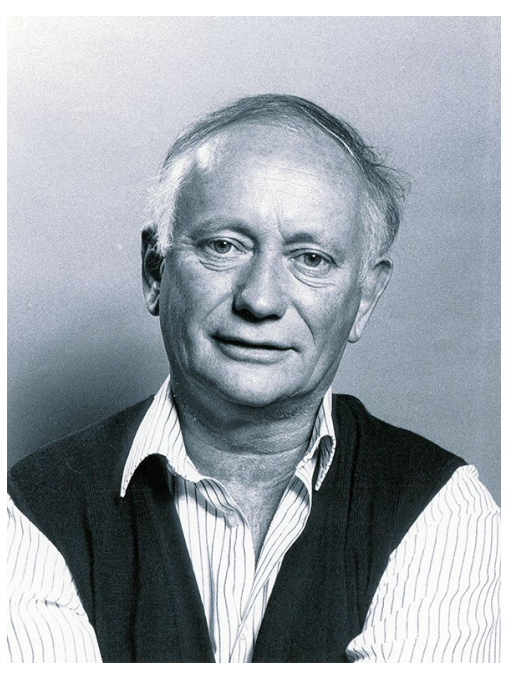

Professor Mike Land FRS (1942-2020). The Royal Society of London, reproduced with kind permission (Photo credit: Colin Atherton, () The University of Sussex).

A little more than a year ago, the field of visual science lost one of its greatest sons-Michael Francis Land FRS, professor emeritus at the University of Sussex in the UK and a dedicated and long-term member of the Editorial Advisory Board of this journal. Mike's enormous legacy to visual science includes his manifold discoveries of all the truly remarkable ways that animal eyes capture, bend, focus and reflect light to create visual images. No corner of the animal kingdom escaped his attentions. Indeed, it was the sheer variety of animals he studied, both aquatic and terrestrial, that was the key to his success. Who apart from Mike would have thought to study the vision of a scallop, an animal that few at the time barely even knew had eyes? But

Handling Editor: Günther K.H. Zupanc.

Eric Warrant

Eric.Warrant@biol.lu.se

1 Lund Vision Group, Department of Biology, University of Lund, Sölvegatan 35, 22362 Lund, Sweden this is precisely what he did, thereby discovering reflecting concave mirror eyes, a brand new optical class of eye for science (Land 1965). We now know of ten different optical classes of eyes in the animal kingdom, and it is fair to say that Mike advanced our understanding of all of them, either by discovering them outright, or by revealing the great diversity of design subtleties and remarkable adaptations that are inherent to each. All of this work, and more, is summarised in his iconic landmark book together with Dan-Eric Nilsson-Animal Eyes (Land and Nilsson 2012) — and in his final wonderful book Eyes to See (Land 2018).

Sadly, though, due to historical bad timing, I did not have the opportunity to get to know Mike as well as many others did, and this is something I regret very much. However, despite this, his influence on me, and on my work, has truly been profound and I owe him an enormous debt of gratitude. Those who were fortunate to know him much better than myself have already written moving obituaries for Mike (Osorio 2021; Nilsson 2021; Marshall and Cronin 2021) and I have no intention of attempting this myself. Instead, I want to pay a very personal homage to a man who, probably without even realising it, was one of my beacons on the hill, a constant source of inspiration, both in science and in writing.

When I say "historical bad timing", I really mean it. It seems that all of my closest friends and colleagues were either students or postdocs of Mike's, or very close collaborators. I came close though, but just not close enough. Towards the end of 1984, as a newly graduated physics major from the University of New South Wales in Sydney, I travelled to Canberra to be interviewed by my future $\mathrm{PhD}$ supervisor, Professor George Adrian Horridge, the famous head of the Department of Neurobiology at the Australian National University. Although Adrian completely sold me on the idea of starting my $\mathrm{PhD}$ on insect vision at the beginning of the following year, one thing did strike me about his department. It seemed unusually empty of people, and later I found out why. Literally the month before my interview, there had been an exodus of famous names back to EuropeSimon Laughlin and Roger Hardie returned to Cambridge, Dan-Eric Nilsson to Lund and Mike Land to Sussex. Mike's 
PhD student David O'Carroll decided to return to Adelaide. I missed them all by a single month. At the time, I had no idea who they were, but it did not take long before the magnitude of this loss really hit home. Thankfully two of them-DanEric Nilsson and David O'Carroll-are now among my closest friends, and we even work in the same buildings in Lund.

My project quickly turned to the optics of superposition compound eyes, under the care of mathematician Peter McIntyre, who taught at the nearby military academy at Duntroon. As I started my project, I soon discovered that two of those famous names that had just left Adrian's department for good also happened to be world authorities on the optics of animal eyes-Mike Land and Dan-Eric Nilsson. My timing could not have been worse. In the years immediately preceding my arrival, Mike and Dan, together with PhD student Joe Howard, had discovered the remarkable afocal apposition compound eyes of butterflies (Nilsson et al. 1984). In addition, using a fabulous "meccano set" of small optical components from the German company Spindler and Hoyer (which came in a gorgeous felt-lined polished wooden case), Mike also built a very clever benchtop ophthalmoscope to peer into the superposition eyes of moths and butterflies. This allowed him to discover that their eyes were diffraction-limited, producing the crispest retinal images that the optics of any eye can provide, thus forever dispelling the idea that superposition eyes were necessarily poorly focussed (Land 1984). Using the same apparatus, Mike also ingeniously discovered the location in the moth's eye where the pupil's light response is controlled (Land 1987), thanking my then fellow PhD student Ted Maddess for "letting him have the moth". Seen in the light of today's merciless demands to verify every finding with large n-values and rigorous statistical tests, Mike's brazen use of a single moth to show the obvious leaves me giggling to this day! Actually, for me, I think this is probably what characterised Mike best. He was a tinkerer, an inventor of cunning devices, the creator of clever experiments that turned the often-fuzzy biological observations that aroused his boundless curiosity into black-and-white physics. Therefore, Mike never needed to use more than that single moth. His optical measurements were so clean, so unambiguous and so persuasive that repeating them all over again on more moths was just a waste of time (and a senseless waste of moths!).

Even though it might sound as though the optics of eyes and the physics of vision would be a dry and difficult topic to communicate, Mike had a way of making it anything but. He always humbly claimed that he received help with the physics and mathematics in his papers from others more versed in these topics, but in actual fact, he was a very able practitioner himself. He was also unusually gifted in using equations to explain optical topics, such as resolution and sensitivity, in a manner that was completely accessible to an interested biologist. His famous sensitivity equation, for instance, has been one of my most trusted theoretical tools for understanding eyes ever since I first encountered it as a $\mathrm{PhD}$ student in Canberra. In my quest to understand the vision of nocturnal and deep-sea animals, I have modified it, built on it and adapted it in so many ways and for so many purposes that I have literally lost track of all the times I have used it.

Then, of course, there is Mike's treasure trove of spectacular papers. You can choose any one of them, it really does not matter which. From the very first sentence, Mike's prose lifts the subject above the dry and mundane style expected of scientific writing, and infuses it with an insatiable joie de vivre for the animals (and their biology) he loved so well. This is why I never tire of reading Mike's papers. The first I ever read, soon after arriving in Canberra, was his exhaustive treatise on the optics of invertebrate eyes (Land 1981), published within the Handbook of Sensory Physiology, a monumental series of books published by Springer during the 1970s and 1980s. This was my first introduction to the eyes of the animal kingdom, and it literally filled me with wonder. What a read! My battered, stained, torn and note-covered photocopy is still one of my most precious possessions. And of course, working on the optics and visual ecology of arthropod eyes, Mike's many other papers on the topic were also must-reads. Whether on krill, amphipods, crayfish, spiders or insects, his papers greatly inspired and influenced my thinking and shaped my research questions. Indeed, they have inspired and shaped my entire career.

This is why, I suppose, it seems so odd to me that I did not have the same personal relationship with Mike that so many others did. His immense influence on me alone would have predicted otherwise. However, sadly, due to that quirk of fate in Canberra so long ago, I was deprived of the years of close personal contact that so many of my dearest friends once had. I have only listened jealously to their tales of sweaty tennis matches with Mike, or of long discussions afterwards over beers. Or of those many afternoon barbecues with Mike and his family at their house in Canberra. Or of the camaraderie in the lab, of inventing new gadgets for investigating eyes and using them to discover amazing new things. I do admit I feel somewhat cheated to have missed out on all of this, and that my relationship with Mike was restricted to brief meetings at conferences, or short visits to Sussex, or via exchanges over email. However, despite this somewhat impoverished contact, Mike was the kindest and most supportive person one could ever wish to meet. I know he reviewed quite a number of my papers and gave excellent advice that improved them significantly. He also wrote letters of support for various promotions, and championed many of our studies in commentaries and other articles. In addition, during those too few visits to Sussex, he and his lovely wife Rosemary always opened their home to me. It was 
really only then that I got to know them. It was also then that I finally realised what I had missed out on all those years before, so close to home, in another time and in another place.

Thank you Mike Land for being my beacon on the hill. You may no longer be with us in person, but your legacy runs deep.

Acknowledgements I wish to thank Dan-Eric Nilsson, one of Mike's closest collaborators and one of my closest friends, for commenting on an earlier version of this manuscript. I would also like to thank the Royal Society of London and the University of Sussex for permission to reproduce Mike's portrait image.

\section{References}

Land MF (1965) Image formation by a concave reflector in the eye of the scallop, Pecten maximus. J Physiol (lond) 179:138-153
Land MF (1981) Optics and vision in invertebrates. In: Autrum H (ed) Handbook of sensory physiology, vol VII/B. Springer, Berlin, pp 471-592

Land MF (1984) The resolving power of diurnal superposition eyes measured with an ophthalmoscope. J Comp Physiol A 154:515-533

Land MF (1987) Screening pigment migration in a sphingid moth is triggered by light near the cornea. J Comp Physiol A 160:355-357

Land MF (2018) Eyes to see. Oxford University Press, Oxford

Land MF, Nilsson DE (2012) Animal eyes. Oxford University Press, Oxford

Marshall J, Cronin T (2021) Michael F. Land (1942-2020). Curr Biol 31:R359-R373

Nilsson DE (2021) Michael Francis Land FRS, 1942-2020. J Exp Biol 224:jeb242427

Nilsson DE, Land MF, Howard J (1984) Afocal apposition optics in butterfly eyes. Nature 312:561-563

Osorio D (2021) Michael Land obituary. The Guardian. https://www. theguardian.com/science/2021/jan/19/michael-land-obituary. Accessed 19 Jan 2021.

Publisher's Note Springer Nature remains neutral with regard to jurisdictional claims in published maps and institutional affiliations. 